the time of contact with the virus may, for reasons as yet unexplained, be incapable of mounting the host/virus response (clinical hepatitis), thus retaining the antigen. It is our experience that when a state of physical health is achieved subsequently by adequate haemodialysis the carrier state nevertheless persists.

It has been hoped that the state of physical health achieved through successful renal transplantation would terminate a prolonged carrier state. Two patients with prolonged antigenaemia, however, have remained carriers of H.A. antigen six and eight months after renal transplantation (J. S. Cameron, personal communication, 1970). The period of stay in hospital for transplantation will put the dialysis population at further risk. Furthermore, transplantation itself may introduce fresh hepatitis by increasing the number of immunosuppressed (and thus infection-prone) patients attached to the unit (Moore and Hume 1969) as well as the possibility of the virus in donor serum contaminating the kidney.

\section{Conclusion}

It is hoped that regular screening for H.A. antigen will avoid the introduction of positive cases into dialysis units and reduce the risk of epidemics. The precautions adopted at this centre include screening of prospective patients and staff as well as donated blood whenever possible. With regard to hygiene, the guidance of the Public Health Laboratory Service Report (1968) has been followed in order to avoid contact with blood and to isolate new cases of hepatitis requiring hospital dialysis. More important, however, is the continued emphasis on home dialysis. Though in this outbreak no relatives of patients with positive H.A. antigen dialysing at home developed hepatitis, they are undoubtedly at risk. Nevertheless, the further development of a self-dialysis technique to include self-venepuncture by patients using a fistula, both at home and in the unit, is a major safeguard.

The use of H.A. antigen has enabled the probable source of this outbreak to be located. In the early detection of fresh cases and in diagnosing the carrier state it has proved invaluable, and has undoubtedly contributed to an earlier termination of an epidemic which in a dialysis population of this size could have reached very much greater proportions.

\section{REFERENCES}

Baillod, R. A., Crockett, R. E., Lee, B. N., Moorhead, J. F., and Stevenson, C. M. (1968). In Dialysis and Renal Transplantation: Proceedings of the 4th Conference of the European Dialysis and Transplant Association, ed. D. N. S. Kerr, p. 30. Amsterdam, Excerpta Medica.

Blumberg, B. S., Alter, H. J., and Visnich, S. (1965). Fournal of the American Medical Association, 191, 541.

Blumberg, B. S., Sutnick, A. I., and London, W. T. (1968). Bulletin of the New York Academy of Medicine, 44, 1566.

Brescia, M. J., Cimino, J. E., Appel, K., and Hurwich, B. J. (1966). New England fournal of Medicine, 275, 1089.

Crockett, R. E., et al. (1968). In Dialysis and Renal Transplantation: Proceedings of the 4th Conference of the European Dialysis and Transplant Association, ed. D. N. S. Kerr, p. 17. Amsterdam, Excerpta Medica.

Drukker, W., Jungenius, N. A., and Alberts, C. (1968). In Dialysis and Renal Transplantation: Proceedings of the 4th Conference of the European Renal Transplantation: Proceedings of the 4th Conference of the European
Dialysis and Transplant Association, ed. D. N. S. Kerr, p. 3. Amsterdam, Excerpta Medica.

Fox, R. A., Niazi, S. P., and Sherlock, 6. (1969). Lancet, 2, 609.

Jones, P. O., Goldsmith, H. J., Wright, F. K., Roberts, C., and Watson, D. C. (1967). Lancet, 1, 835.

London, W. T., Difiglia, M., Sutnick, A. I., and Blumberg, B. S. (1969). New England fournal of Medicine, 281, 571

Moore, T. C., and Hume, D. M. (1969). Annals of Surgery, 170.

Morgenstern, S., Oklander, M., Auerbach, J., Kaufman, J., and Klein, B. (1966). Clinical Chemistry, 12, 95.

Prince, A. M. (1968a). Lancet, 2, 462.

Prince, A. M. (1968b). Proceedings of the National Academy of Sciences of the United States of America, 60,814 .

Public Health Laboratory Service Report (1968). British Medical fournal,

3, 454.
Quinton, W. E., Dillard, D. H., Cole, J. J., and Scribner, B. H. (1962). Transactions American Society for Artificial Internal Organs, 8, 236. Turner, G. C., and White, G. B. B. (1969). Lancet, 2, 121.

\title{
Glucose and Insulin Secretory Response Patterns Following Diet and Tolazamide Therapy in Diabetes
}

\author{
J. R. TURTLE, ${ }^{*}$ M.D., M.R.A.C.P.
}

Summary: Glucose and insulin secretory response $\checkmark$ patterns during glucose tolerance tests were determined in 28 maturity-onset diabetics, and the sequential effects of diet and a sulphonylurea, tolazamide, were assessed. Untreated diabetics showed hyperglycaemia, increased serum immunoreactive insulin response patterns, delayed insulin release, and relative insulin deficiency. Diet alone partially corrected the hyperglycaemia and serum immunoreactive insulin response but had no effect on the delayed insulin release or relative insulin deficiency. Tolazamide plus diet restored all values towards normal. The net effect of maintenance tolazamide therapy was to $(1)$ restore the insulin secretory response pattern to normal, (2) reduce total pancreatic insulin output, and (3) improve the efficiency of insulin secretion. The results suggest that there is a rational basis for the use of sulphonylurea in all maturityonset diabetics, including patients with mild carbohydrate intolerance and those who are apparently controlled by diet alone.

* Senior Lecturer in Medicine, University of Sydney; Honorary Physician, Royal Prince Alfred Hospital, Camperdown, N.S.W., Australia.

\section{Introduction}

The management of maturity-onset diabetes mellitus has been facilitated in the past 15 years following the introduction of the sulphonylurea group of compounds. The clinical indications for therapy with these drugs are not yet clearly defined, though their use for the control of hyperglycaemia in maturity-onset diabetes is well established.

Tolazamide is a sulphonylurea closely related to tolbutamide (Fig. 1). After injection the biological half-lives of both drugs are similar (about seven hours) (Weaver, 1966). Owing to the slow absorption of tolazamide from the gastrointestinal tract a daily dose of 50 to $600 \mathrm{mg}$. is usually satisfactory for the control of hyperglycaemia in maturity-onset diabetes mellitus. The hypoglycaemic action reaches a peak between 4 and 16 hours after an oral dose; however, an effect can still be observed for 24 hours. McKendry and Gfeller (1967) reported that the clinical effectiveness of tolazamide was comparable to tolbutamide and that good or excellent control of hyperglycaemia could be achieved in $56 \%$ of diabetics. Tolazamide is about seven times as potent as tolbutamide. Doses as high as $1,000 \mathrm{mg}$. daily have been used without evidence of toxicity (McMahon et al., 1962; Rennie and Anderson, 1963; Grinnell et al., 1964; Weaver, 1966; McKendry and 

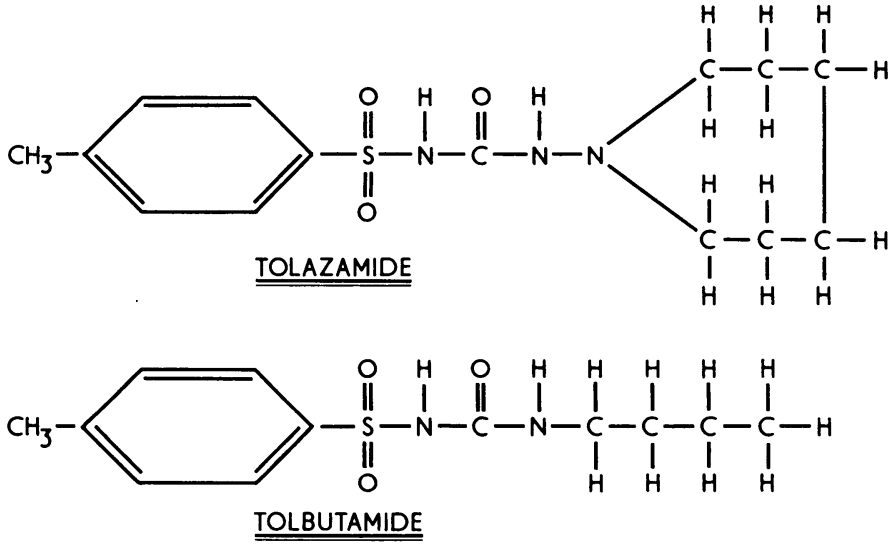

FIG. 1.-Structural formulae for tolazamide and tolbutamide.

Gfeller, 1967). It has been given in combination with biguanides to control hyperglycaemia in patients who are relatively resistant to sulphonylureas alone (Weaver, 1966).

As tolazamide is a safe, potent, and non-toxic sulphonylurea, it was selected for the present study. The serum insulin secretory response patterns were determined in maturity-onset diabetes, then the acute and long-term effects of diet and tolazamide were evaluated in an attempt to define precisely the hypoglycaemic and insulinogenic actions of the sulphonylureas.

\section{Patients and Methods}

Twenty-eight patients aged 22 to 63 were selected for study. In all cases a diagnosis of non-ketotic diabetes mellitus had been made on the basis of abnormal blood glucose response to an oral glucose load of $100 \mathrm{~g}$., using the criteria of the American Diabetes Association. All had a fasting blood glucose greater than $100 \mathrm{mg} . / 100 \mathrm{ml}$, exceeding $160 \mathrm{mg}$. at either 30 or 60 minutes, $120 \mathrm{mg}$. at 90 minutes, and $110 \mathrm{mg}$. at 120 minutes. Ketonuria was absent. No patient had been treated for diabetes mellitus previously and body weight was within $15 \%$ of the mean for weight and age.

Diet.-After initial investigations were completed each patient was started on a diet containing $30 \%$ carbohydrate with a caloric allowance of 30 calories per $\mathrm{kg}$. of ideal body weight. Patients more than $10 \%$ above ideal weight were restricted to 20 calories per $\mathrm{kg}$. of ideal body weight.

Sulphonylurea.-Fourteen to 21 days after the diet was begun tolazamide was started in a single daily dose of 125 to $750 \mathrm{mg}$., taken 30 minutes before breakfast. After the hyperglycaemia had been controlled a maintenance dose of tolazamide was established. This was defined as the minimum amount of tolazamide required to achieve a twohour postprandial blood glucose concentration of $120 \mathrm{mg} . / 100 \mathrm{ml}$. or less.

\section{Experimental Procedure}

All patients were given a high carbohydrate diet for 48 hours. This was followed by an overnight fast, then an oral glucose tolerance test was performed. The test dose was $100 \mathrm{~g}$. of glucose as a $50 \%$ solution. The glucose tolerance test was repeated three weeks after starting a $30 \%$ carbohydrate diet and again three to four months after starting tolazamide. In three patients a $50-\mathrm{g}$. intravenous glucose tolerance test was performed on the day before tolazamide was introduced, being repeated on days $1,2,3$, and 7 after the drug was started in a daily dose of $250 \mathrm{mg}$.

All patients had an indwelling venous catheter in an antecubital vein throughout each test procedure. Frequent blood samples were taken for the estimation of blood glucose and serum immunoreactive insulin (I.R.I.). Glucose was measured by the alkaline ferricyanide method of Hoffman (1937) with an AutoAnalyzer. Serum I.R.I. was measured by the double antibody radioimmunoassay of Morgan and Lazarow (1963).

Insulin secretion was estimated during the periods of study by a modification of the insulinogenic indices method of Seltzer et al. (1967) and Glueck et al. (1969). Curves were produced for insulin and glucose responses by smoothing the values obtained at each point during the glucose tolerance tests. The areas subtended by these curves were measured by planimetry. Expressions were obtained for glucose as milligrams-minutes per millilitre and for I.R.I. as microunitsminutes per millilitre. A more accurate estimate of insulin secretion was derived by relating the area under the insulin response curve to that under the glucose response curve. Insulin secretion could then be expressed in terms of the absolute glucose levels as microunits I.R.I. per mg. glucose per ml. (I.R.I./G.).

\section{Results}

Clucose Tolerance on Presentation.-Blood glucose and serum I.R.I. levels obtained during the initial glucose tolerance tests in 28 patients are shown in Fig. 2. Normal glucose and I.R.I. response curves are shown by the shaded area. Whereas there was a prompt increase in serum I.R.I. in normal persons the response was delayed in maturity-onset diabetics. The peak serum I.R.I. concentration was considerably greater in the diabetic group than in normal controls. Similarly the area subtended by the insulin concentrations was greater than normal in the diabetics. The insulin/glucose (I.R.I./G.) ratio was $15.2 \mu$ unit-mg. $/ \mathrm{ml}$. in diabetics, or $62 \%$ of the normal 24.6 $\mu$ unit-mg./ml. (Table I). With these criteria the maturity-onset diabetics were relatively insulin-deficient.

Effect of Diet.-In 18 patients the glucose tolerance tests were repeated after three weeks of diet (Fig. 3). Reduction in carbohydrate intake and total calories reduced the integrated
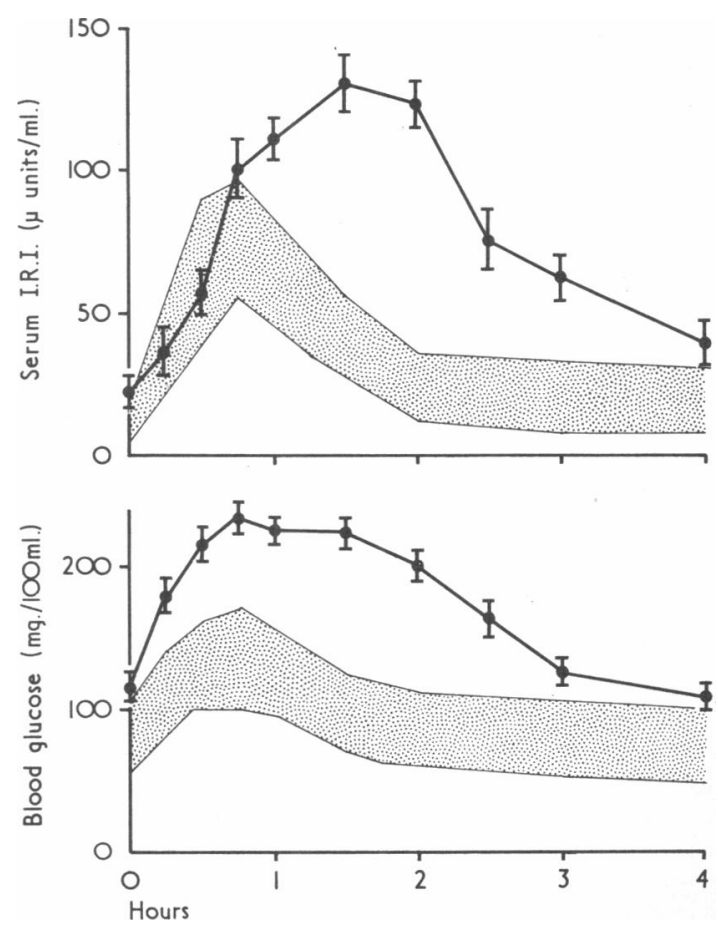

Fig. 2.-Blood glucose and serum I.R.I. response curves during glucose tolerance tests ( $100 \mathrm{~g}$. glucose) in 28 maturity-onset diabetics. Each point represents the mean \pm .E. of mean. The shaded area is the range obtained in the 10 normal volunteers. 
glucose response by $34 \%$, from $1,143 \pm 65 \mathrm{mg}$.-min. $/ \mathrm{ml}$. on presentation to $755 \pm 29 \mathrm{mg} .-\mathrm{min} . / \mathrm{ml}$. in three weeks (Table I). Total I.R.I. secretion was reduced by $29 \%$, from 17,355 to $12,302 \mu$ units-min./ml. The I.R.I./G. ratio remained unchanged after diet alone and relative insulin deficiency persisted. Diet did not alter the delayed I.R.I. response to a glucose load (Figs. 2 and 3 ).

TABLE I.-Effect of Diet and Tolazamide on Blood Glucose, Serum I.R.I., and I.R.I./Glucose Ratios During Oral Glucose Tolerance Tests in Maturity-Onset Diabetics

\begin{tabular}{|c|c|c|c|}
\hline & $\begin{array}{c}\text { Glucose Response } \\
(\text { mg. }- \text { min./ml. } \\
\text { mean } \pm \text { S.E. of mean })\end{array}$ & $\begin{array}{l}\text { I.R.I. Response } \\
\text { ( } \mu \text { units-min./ml. } \\
\text { mean } \pm \text { S.E. of mean) }\end{array}$ & $\begin{array}{c}\text { I.R.I./Glucose } \\
\text { Ratio } \\
\text { (uunits-mg./ml.) }\end{array}$ \\
\hline $\begin{array}{l}\text { Normal (10) } \ldots \\
\text { Untreated } \\
\text { maturity- } \\
\text { onset } \\
\text { diabetics (28) } \\
\text { Diet alone: } \\
18-21 \text { days (18) } \\
100-120 \text { days } \\
\text { (5) } \ldots \text {. } 0 \\
\text { Diet and tolaz- } \\
\text { amide (20) . }\end{array}$ & $\begin{array}{r}1,143 \pm 65 \\
755 \pm 29 \\
713 \pm 36 \\
323 \pm 17\end{array}$ & $\begin{array}{r}17,355 \pm 210 \\
12,302 \pm 203 \\
11,845 \pm 345 \\
7,345 \pm 136\end{array}$ & $\begin{array}{l}16 \cdot 3 \\
16 \cdot 6\end{array}$ \\
\hline
\end{tabular}

Effect of Maintenance Tolazamide Therapy.-In 20 patients treated with diet and tolazamide for three to four months a further glucose tolerance test showed that both the glucose and I.R.I. response curves had returned towards normal (Fig. 4). Five patients were maintained on diet alone for 100 to 120 days (Fig. 5). In these patients the glucose and I.R.I. curves were similar to those obtained after three weeks of diet. Tolazamide reduced the glucose response by $69 \%$, from 713 to $323 \mathrm{mg} .-\mathrm{min} . / \mathrm{ml}$, and the I.R.I. response by $38 \%$, from 11,845 to $7,345 \mu$ units-min./ml., when compared with diet alone for three to four months (Table I). It is notable that tolazamide reduced the glucose response to a greater extent than the I.R.I. response; consequently the I.R.I./G. ratio increased (Table I). The net effect of tolazamide plus diet was a pronounced improvement in the relative insulin deficiency, the I.R.I./G. ratio returning to an almost normal value of $22.7 \mu$ units $-\mathrm{mg}$. $/ \mathrm{ml}$. Instead of the pronounced delay in the serum I.R.I. secretory response pattern in untreated or diet-treated diabetics, partial correction towards normal was seen after tolazamide (Fig. 4).

Early Effects of Tolazamide.-In three patients there was a
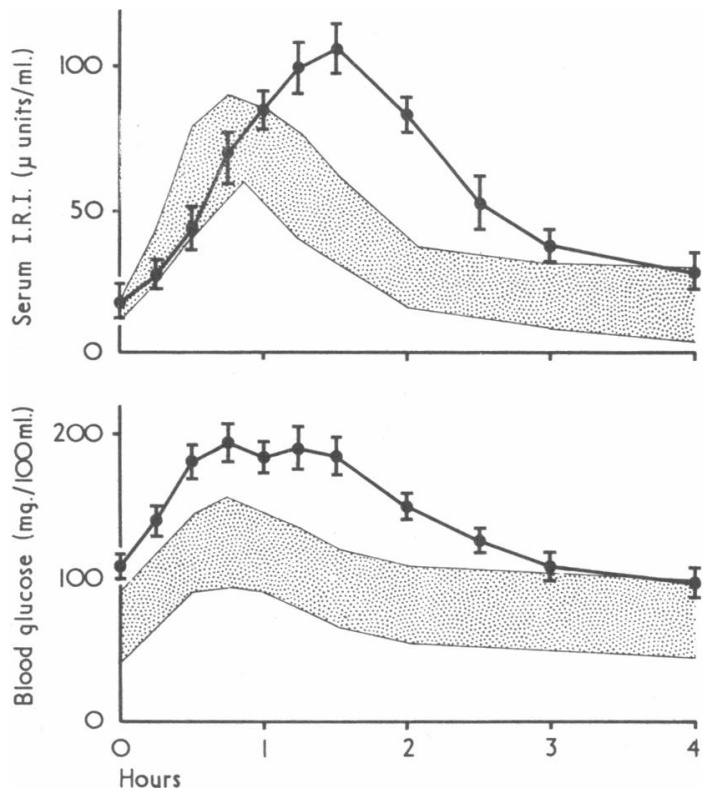

Fig. 3.-Effect of diet alone for three weeks during oral glucose tolerance tests in 18 patients. Each point represents the mean $+\mathrm{S}$. E. of mean. The shaded area is the normal range.
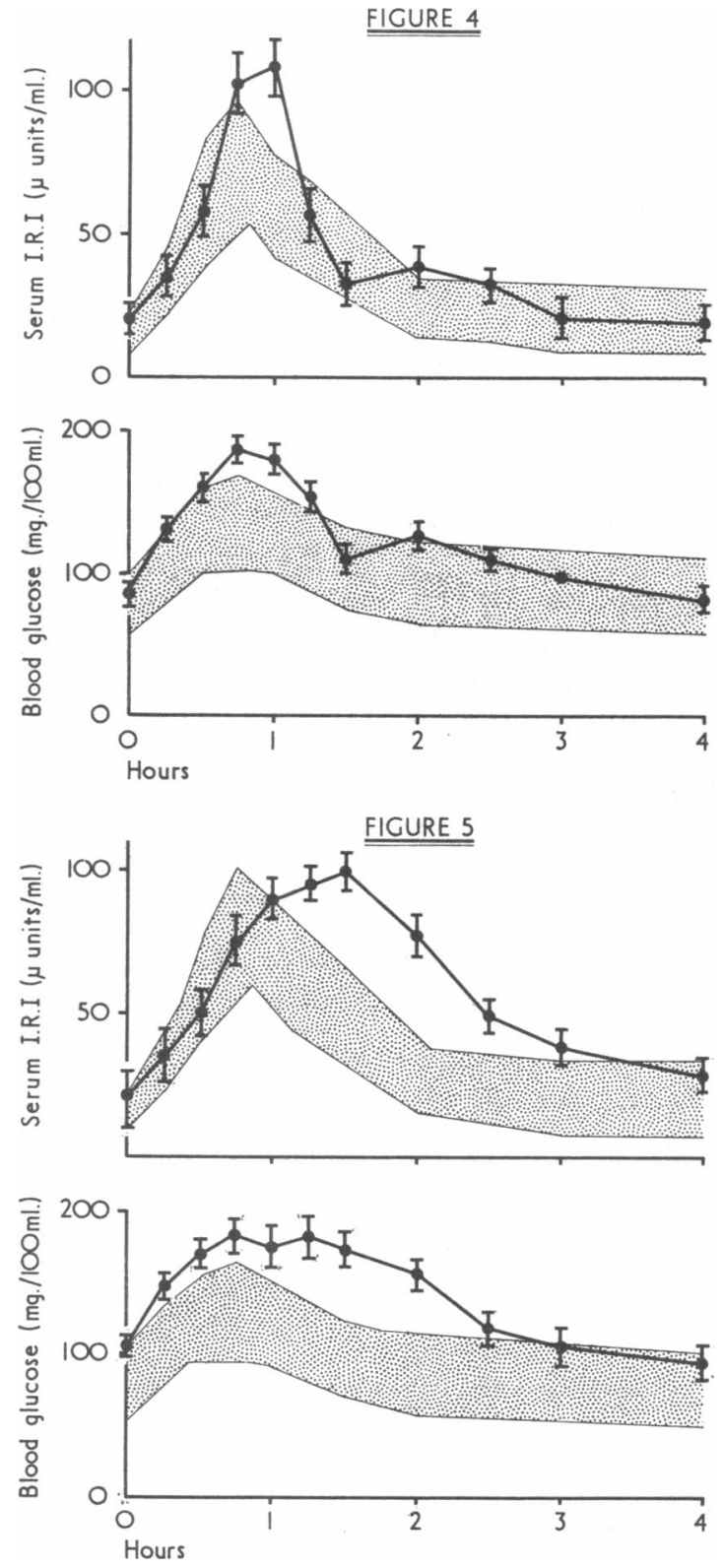

Fig. 4.-Effect of tolazamide and diet during oral glucose tolerance tests in 20 patients. Tests were performed after three to four months of therapy. Each point represents the mean $t$ S.E. of mean. The shaded area is the normal range. FIG. 5.-Effect of diet alone for three to four months during oral glucose tolerance tests in five patients. Each point represents the mean \pm S.E. of mean. The shaded area is the normal range.

pronounced increase in the I.R.I. response to intravenous glucose $(50 \mathrm{~g}$.$) injected three hours after the first tablet of$ tolazamide $250 \mathrm{mg}$. Coinciding with this I.R.I. response there was a fall in blood glucose (Fig. 6). When the intravenous glucose load was repeated on subsequent days there was a progressive fall in the I.R.I. response. The glucose response decreased slightly. Before treatment the peak serum I.R.I. concentration was not reached until 45 minutes after glucose injection. The first dose of tolazamide accelerated the I.R.I. response, the peak being reached about 10 minutes after glucose (Fig. 6). The I.R.I./G. ratio increased sharply after tolazamide was started; but it fell progressively during the first week of treatment (Table II). After seven days the I.R.I. response had fallen from a peak of 4,255 to $3,050 \mu$ units$\mathrm{min} . / \mathrm{ml}$., almost to the pretreatment level of $2,875 \mu$ units$\mathrm{min} . / \mathrm{ml}$. The fall in the glucose response from a peak of 175 to $163 \mathrm{mg}$.-min./ml. was not significant, however, both values being significantly lower than the pretreatment level of $237 \mu$ units-min./ml. The net result was an increased I.R.I./G. 

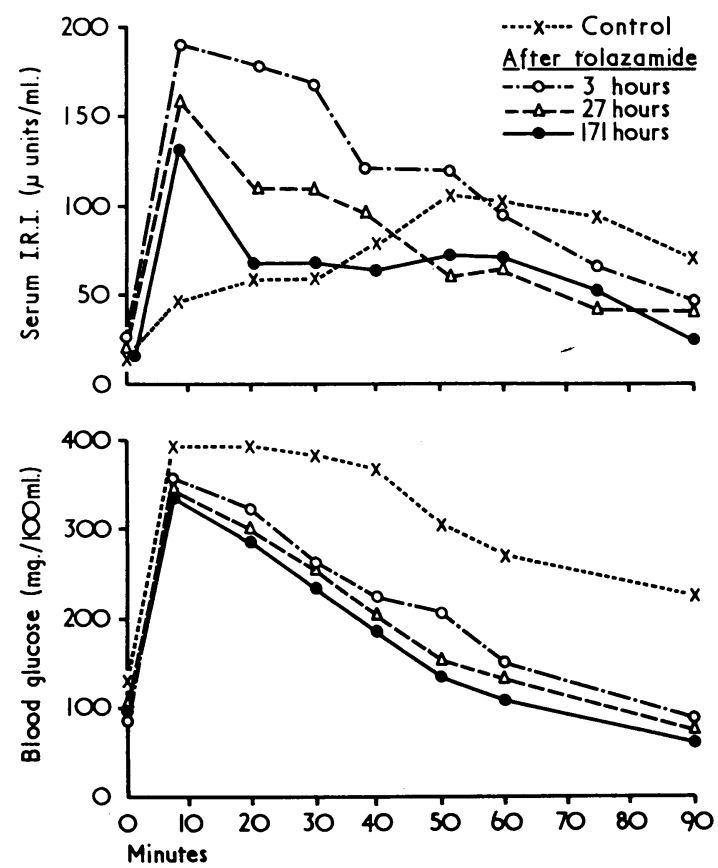

Fig. 6.-Early effects of tolazamide on glucose and I.R.I. response curves in three patients given an intravenous injection of glucose $(50 \mathrm{~g}$.) before treatment, then 3,27 , and 171 hours after starting tolazamide $250 \mathrm{mg}$. daily. Each point represents the mean of the three estimations.

ratio from $12.1 \mu$ units $-\mathrm{mg} . / \mathrm{ml}$. before treatment to 18.7 at the end of the first week of tolazamide treatment.

Side-effects of Tolazamide.-During the period of the study 28 patients were given tolazamide in maintenance doses of 125 to $750 \mathrm{mg}$. daily for periods of 3 to 21 months. The drug was used for a total of 364 patient-months with minimal sideeffects. One patient developed symptomatic hypoglycaemia (blood glucose $48 \mathrm{mg} . / 100 \mathrm{ml}$.) on a dose of $125 \mathrm{mg}$. of tolazamide daily. The hypoglycaemia was relieved by substituting tolbutamide $1 \mathrm{~g}$. daily for tolazamide. A second patient noticed mild nausea repeatedly 60 minutes after taking tolazamide. There was no change in peripheral blood or in renal or hepatic function during the study.

\section{Discussion}

Despite 15 years of widespread use of sulphonylureas for the treatment of maturity-onset diabetes mellitus (Bernhard, 1965) it has not been possible to define a clear mechanism of action for this group of hypoglycaemic drugs. Several actions are now well recognized: (1) sulphonylureas cause hypoglycaemia in the normal animal owing to stimulation of the pancreatic islet beta cells (Loubatières, 1944); (2) they depend on the presence of the pancreas for their hypoglycaemic action and they are totally ineffective in the pancreatectomized dog (Loubatières, 1944); and (3) they stim-

TABLE II.-Acute Effects of Tolazamide on Blood Glucose, Serum I.R.I., and I.R.I./Glucose Ratios Following Intravenous Glucose in Three Patients

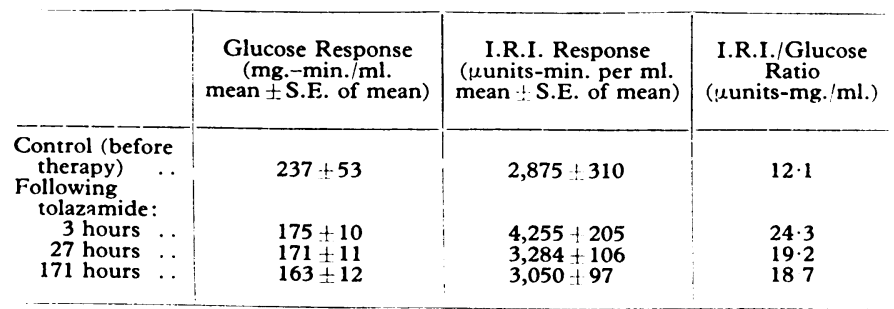

ulate insulin release from pancreatic tissue in vitro (Coore and Randle, 1964) and cause beta cell degranulation and emiocytosis of islet beta granules (Williamson et al., 1961). In spite of the recognized hypoglycaemic and pancreatic islet beta cytotrophic action of the sulphonylureas, little is known of the precise effect of these drugs on pancreatic islet metabolism. Montague and Taylor (1969) and Idahl (1970) reported that tolbutamide increased the concentration of both glucose6-phosphate and 6-phosphogluconate in rat pancreatic islets. These studies suggest that glycolysis and possibly an alternate pathway for glucose metabolism are necessary for insulin releases. The actions of tolbutamide may be mediated by acceleration of glucose-6-phosphate oxidation via a 6-phosphogluconate pathway.

The untreated maturity-onset diabetics in the present study showed a pronounced rise in both glucose and I.R.I. responses during a glucose tolerance test. The I.R.I./G. ratio was lower than normal, indicating relative insulin deficiency. These findings are similar to those reported by Ricketts $e t$ al. (1966). In addition to the insulin deficiency there was a characteristic sluggish insulin response to glucose (Cerasi and Luft, 1967). Both these findings are consistent with a gross derangement in the normal pancreatic islet insulin secretory mechanism. Diet effectively reduced both the diabetic glucose and I.R.I. responses, but there was no change in the I.R.I./G. ratio, and the delaved insulin response remained unchanged. Thus diet alone had no effect on the efficiency of the pancreatic insulin secretory mechanism, and the state of relative insulin deficiency persisted.

When tolazamide was given in addition to diet, both glucose and I.R.I. responses decreased to a greater extent than they did with diet alone. The glucose response was decreased more than the I.R.I. response and consequently there was an increase in the I.R.I./G. ratio; in other words, the efficiency of insulin secretion was improved. Coincident with the correction of relative insulin deficiency, the delayed pancreatic insulin response returned towards normal. Tolazamide changed the insulin response to glucose immediately after the drug was given. Three hours after the first dose there was a considerable improvement in the delayed I.R.I. response to intravenous glucose. In addition, the I.R.I./G. ratio increased promptly. During the first week of therapv the I.R.I. response decreased towards the pretreatment level; the I.R.I./G. ratio, however, fell only slightly. Improvement in the efficiency of the insulin secretory mechanism was maintained.

The action of tolazamide in maturity-onset diabetes was to restore the pancreatic insulin response to a glucose load to a normal pattern. As a result of this action the relative insulin deficiency returned towards normal. This state of improved efficiency of insulin secretion could not be achieved by diet alone. These results suggest that the sulphonylureas have a rational place in the treatment of maturity-onset diabetics and in the treatment of those patients who are apparently controlled on diet. In these patients the sulphonylureas increase the overall efficiency of insulin secretion. It is interesting that increased efficiency is achieved though there is an overall decrease in the I.R.I. response. Fajans and Conn (1960) suggested that sulphonylureas may have a place in the treatment of persons with mild carbohydrate intolerance to prevent ultimate breakdown to frank diabetes mellitus. The present study supports the concept of Fajans and Conn, as the net effect of the sulphonylurea therapy was to reduce pancreatic load while restoring insulin and glucose responses towards normal.

The co-operation of the medical staff of Royal Prince Alfred Hospital is gratefully acknowledged. Dr. Trevor J. S. Smith, Medical Director of Upiohn Proprietary Limited, generously supplied the sulphonylurea tolazamide (Tolanase). Miss Alison Stewart provided valuable technical help. 
Bernhard, H. (1965). Diabetes, 14, 59.

Cerasi, E., and Luft, R. (1967). Diabetes, 16, 615

Coore, H. G., and Randle, P. J. (1964). In The Structure and Metabolism of the Pancreatic Islets, ed. S. E. Brolin, p. 295, Oxford, Pergamon Press.

Fajans, S. S., and Conn, J. W. (1960). Diabetes, 9, 83.

Glueck, C. J., Levy, R. I., and Fredrickson, D. S. (1969). Diabetes, 18, 739.

Grinnell, E. H., Skillman, T. G., Barse, R., and Moller, C. L. (1964). Current Therapeutic Research, 6, 433.

Hoffman, W. S. (1937). Fournal of Biological Chemistry, 120, 51.

Idahl, L. A. (1970). In The Structure and Metabolism of the Pancreatic Islets. In press.

Loubatières, A. (1944). Comptes Rendus des Séances de la Société de Biologie et de Ses Filiales, 138, 766.
McKendry, J. B. R., and Gfeller, K. F. (1967). Canadian Medical Association Journal, 96, 531 .

McMahon, F. G., et al. (1962). Current Therapeutic Research, 4, 330.

Montague, W., and Taylor, K. W. (1969). Biochemistry fournal, 115, 257.

Morgan, C. R., and Lazarow, A. (1963). Diabetes, 12, 115.

Rennie, C. S., and Anderson, D. O. (1963). Canadian Medical Association fournal, 89, 669.

Ricketts, H. T., Cherry, R. A., and Kirsteins, L. (1966). Diabetes, 15, 880. Seltzer, H. S., Allen, E. W., Herron, A. L., and Brennan, M. T. (1967). fournal of Clinical Investigation, 46, 323.

Weaver, J. A. (1966). Clinical Trials fournal, 3, 453

Williamson, J. R., Lacy, P. E., and Grisham, J. W. (1961). Diabetes, 10, 460.

\title{
Acid Production in Diabetic Acidosis; a More Rational Approach to Alkali Replacement
}

\author{
P. Z. ZIMMET,* M.B., M.R.A.C.P. ; P. TAFT, $\dagger$ M.D., F.R.A.C.P. ; G. C. ENNIS, $\ddagger$ M.B., M.R.A.C.P. \\ J. SHEATH, $\$ M.SC., F.A.A.C.B.
}

British Medical fournal, 1970, 3, 610-612

\begin{abstract}
Summary: The production of organic acids in severe diabetic acidosis was studied to determine the contribution of various acids and to reassess alkali requirements. In 11 patients the mean total concentration of determined organic acids was $16 \mathrm{mEq} / 1$., while the mean estimated base deficit was $24 \mathrm{mEq} / 1$. Acetoacetic and $\beta$-hydroxybutyric acids accounted for $75 \%$ of measured organic acid. In 10 patients the mean amount of sodium bicarbonate administered for correction of the acidosis was $185 \mathrm{mEq}$, while the mean requirement was 394 mEq.

These findings imply that the methods commonly used to determine the base deficit and the alkali requirements in patients with diabetic acidosis may be invalid. The prompt administration of alkali should be limited, and we suggest that the blood $p H$ should be restored only to $7 \cdot 25$.
\end{abstract}

\section{Introduction}

In diabetic acidosis, acetoacetic, $\beta$-hydroxybutyric, and other acids are formed in the liver more quickly than they can be utilized in the peripheral tissues or excreted by the kidney. The accumulation of these acids in the body fluids has generally been accepted as the cause of the acidosis in this condition (Nabarro, 1965). Concurrently with insulin and fluid therapy, the administration of alkali is a well-recognized emergency measure for correction of the metabolic acidosis (Hudson et al., 1960). One of the main problems associated with alkali therapy is the difficulty in assessing the quantity of alkali to be administered.

The purpose of this study was to determine the contribution of various organic acids to the acidosis of diabetic acidosis and to reassess alkali requirements in the light of our findings.

\section{Patients and Methods}

Eleven patients with severe diabetic acidosis were studied The biochemical criteria for the diagnosis of diabetic acidosis -arterial blood $p H$ less than 7.2 and/or plasma bicarbonate

* Research Fellow.

+ Physician-in-Charge.

Former Research Fellow.

Research Biochemist.

Ewen Vuntralia 3181 less than $10 \mathrm{mEq} / \mathrm{l}$. (Bondy, 1963)-were satisfied in each case. These values, together with initial blood sugar concentrations, are shown in Table I. There were seven females and four males, with an age range from 10 to 74 years. Patients were treated along lines previously suggested (Taft et al., 1968).

Arterial blood samples were obtained from the femoral artery with a heparinized syringe. Samples were taken before treatment and at 4 and 20 hours during treatment. Blood $p H$ and $\mathrm{PCO}_{2}$ were measured immediately by the Radiometer microelectrode system. Blood lactic and pyruvic acid levels were measured by an enzymatic method (Boehringer Corporation Ltd.) and free fatty acids by a colorimetric method (Sheath, 1965). Acetoacetic and $\beta$-hydroxybutyric acids were separately converted to acetone and measured spectrophotometrically, as the 2-4 dinitrophenylhydrazone of acetone (Paterson et al., 1967). Blood sugar was measured by a ferricyanide procedure.

The severity of the acidosis and the clinical response to the first bicarbonate dose determined the extent of further alkali therapy. In general, patients with an initial arterial $\mathrm{pH}$ greater than 7.2 received no further alkali, patients with $p H \mathbf{H}$ to 7.2 received a further 44 to $88 \mathrm{mEq}$ and those with $\mathrm{pH}$ less than 7.1 received 110 to $176 \mathrm{mEq}$. The result of this therapy was checked with another $p \mathrm{H}$ reading four hours after the start of treatment. No further alkali was required by any of the patients.

\section{Results}

Blood Concentrations of Organic Acids on Admission.-The concentrations of the measured organic acids at the time of admission and the mean total of measured organic acid are given in Table II.

Difference between Blood Base Deficit and Measured Organic Acid.-The difference between blood base deficit calculated from the Siggaard Andersen acid-base alignment nomogram (Siggaard Andersen, 1963) and the total measured organic acid is shown in Table III. The mean difference of $8 \mathrm{mEq} / \mathrm{l}$. between the mean blood base deficit and the mean total measured acid represents the discrepancy between excess acid values predicted from the nomogram and those measured. 